\title{
Communicative Informatics: An Active and Creative Audi- ence Framework of Social Media
}

\author{
Linda M. Gallant ${ }^{1}$ \& Gloria M. Boone ${ }^{2}$
}

${ }^{1}$ Linda_Gallant@emerson.edu

2gboone@suffolk.edu

\begin{abstract}
Communicative informatics reflects the interactive complexity of web-based communication and a paradigm shift away from mass communication. Three discursive spheres (database and information systems, human computer interaction, and active audiences) work together to control online communication openness and its consequences for post-mass media society's public common. This has implications for communication freedom, creativity, and constraints in an information-based society. Four propositions shed light on how online audience activity is encouraged by and imperative to corporate interests; how audience creativity can create, accept, or reject messages; how the online audience is monitored; and how online rhetoric can produce or inhibit public commons. Evidence shows that social media's corporate interests can be at odds with online privacy and citizen communication. This tension is explored with a unique focus on rhetoric, argument, and the communication between audience members and Internet-based corporate media by way of digitized communication feedback loops.
\end{abstract}

Keywords: Social Media, Audience, Communication Theory, Rhetoric, Internet, Commoditization, Communicative Informatics, Creativity, Surveillance, Persuasion, User-Generated Content.

Acknowledgement: The authors would like to thank colleagues, reviewers, and editors for comments on this article. This manuscript is based on a competitively selected paper presented in the Communication and the Future Division of the National Communication Association, for San Diego, 2008 conference.

\section{Introduction}

Web-based interactive technologies challenge traditional frameworks for the study of human discourse (Kim \& Weaver, 2002; LaRose \& Eastin, 2004; Parameswaran \& Whinston, 2007; Qvortrup, 2006; Steers, Meyer, \& Sanchez-Runde, 2008). Researchers such as Benkler (2006; 2000) and Lessig (2008; 2006; 2005; 2001) presented layered and active/passive audience models to examine Internet communication from a legal and economic perspective. A complement to these frameworks is to examine social media using a rhetorical-based approach - communicative informatics.

Benkler states: "We are making regulatory choices at all layers of the information environment the physical infrastructure, logical infrastructure, and content layers - that threaten to concentrate the digital environment as it becomes more central to our social conversation.... An open, free, flat, peer-to-peer network best serves the ability of anyone - individual, small group, or large group - to come together to build our information environment. It is through such open and equal participation" that we will best secure both robust democratic discourse and individual expressive freedom" (Benkler, 2000, p. 561). Benkler continues to discuss this legal and economic layer model of online networks in his acclaimed book, The Wealth of Networks. He discusses the enclosures that limit communication in the Internet commons by ISP liability, regulatory requirements, patents, copyright, database protections, and other legal frameworks; and the openness of online communication provided by wireless networks, free software, W3C, The Creative Commons, and the widespread social disdain for copyright (Benkler, 2006, p.395).

Based on Benkler's work, Lessig, in The Future of ldeas, uses a layer communication model. He states: "At the bottom is a 'physical' layer, across which communication travels. This is the computer, or wires, that link computers on the Internet. In the middle is a 'logical' or 'code' layer - the code that makes the hardware run. Here we might include the protocols that define the Internet and the software upon which those protocols run. At the top is a 'content' layer - the actual stuff that gets said or transmitted across these wires. Here we include digital images, texts, on-line movies, and the like. These three layers function together to define any particular communications system. Each of these layers in principle could be controlled or could be free. Each, that is, could be owned or 
each could be organized in a commons" (Lessig, 2001, p. 23). Lessig continues his legal analysis in his other books: on how code creates a legal pattern for regulation of online communication in Code 2.0. (2006); the evolution of copyright especially in the music industry in Free Culture (2005); and the legal differences of Read/Only and Read/Write in his book Remix (2008). In all of these books Lessig argues for changing copyright laws to allow for more creative expression for noncommercial use to copy or remix.

By building on the ideas of Benkler and Lessig, one could construct a new layer model of communication that examines the rhetorical content of the active audience; the human computer interaction, and database information systems. This model, communicative informatics, focuses on rhetoric, persuasion, creativity, advertising, and corporate control of communication in social media.

As noted by Lessig (2004, p. 185), privacy has decreased and creativity on the Internet is not as free as possible because of regulation. However, creativity has changed in a positive direction -

more than Lessig seems to suggest. One reason is economic. Audience activity and creativity is needed in order for corporate social media to be profitable.

Although Lessig (2006, p. 83), maintains that the Internet has not fundamentally changed people's lives, other research suggests that life and death decisions can occur due to online heath persuasion (Gallant, et al, 2010; Gallant, Irizarry, \& Boone, 2008).

Livingstone (2006) explains that the passive audience research models of traditional mass media research centered on the one-way reception of media messages must be replaced by an active audience research perspective to study online two-way communication. Moreover, scholarship confirms that online audiences are active users and not passive viewers of media (see, Aibar, 2010; Boone, 2004; Boone \& Gallant, 2007; Deuze, 2006; Harrison \& Barthel, 2009; Livingstone, 2004). Although theorists and researchers in the $20^{\text {th }}$ Century were concerned with one-way mass communication on target audiences, a new analysis of how corporate-owned social media facilitates, monitors, persuades, and influences active audiences and citizenry is needed today.

The communicative informatics model has a unique focus on rhetoric, argument, and the communication by and to the audience. It is a generative model, which explicitly calls attention to digitized communication feedback loops between audience members and Internet-based corporate media. Three discursive spheres (database and information systems, human computer interaction, and active audiences) work together to control online communication openness and its consequences for post-mass media society's public common. Society entered an era of post-mass media with the creation of the online digitized feedback loop. Audience communication is an automated two-way form of communication and can be captured, stored, analyzed, and owned by corporate media companies. The digitized accumulation of private and public communication holds implications for consumers and citizens since the transparency of audience data use is obscured by laws protecting proprietary corporate technologies. Communicative informatics reflects the interactive complexity of web-based communication and is a paradigm shift away from mass communication which, although still a vital area of study, has been subsumed by new media.

No longer can we understand personal and mass communication without considering the new multi-channel, multi-directional, multi-modal, and multi-time (synchronous and asynchronous) communication formats that are processed and analyzed by corporate information systems. Analysis of online communication must integrate two disciplines: human communication and information sciences. Merging these disciplines provides a more holistic understanding of how databasedriven, post-mass media have an impact on a globally networked society by facilitating human communication through complex information systems.

To present a new communicative informatics framework, we will: define communicative informatics; describe the three discursive sphere of communicative informatics (information systems and database analysis of user data, human computer interaction design, and rhetorical communication); and present four propositions about post-mass media audience. We also will cover how an active and creative audience is monitored and its implications for public communication and public commons. Even though governments can control and analyze Internet communication, we primari- 
ly focus our attention on corporate control of online communication to investigate the implications of commoditizing private and public communication through social media.

\section{Communicative Informatics}

Communication is the basis of human organizing (Gallant, 2006) and, online, people communicatively engage more in cultural production than with any older more passive traditional media (Benkler, 2006). Globally, social networks and blogs are visited by three-quarters of consumers who go online worldwide (Nielsen, 2010a) and are the most popular web-based information spaces when ranked by average time spent online, followed by online games, and instant messaging (Nielsen, 2010b). Time spent using social media is surpassing online searches as evidenced by people spending more time on Facebook than in searching on Google (ComScore, 2010). This increase in social media use by active audience members is unleashing a torrent of user-generated content. As Siegler (2010) notes: "Every two days now we create as much information as we did from the dawn of civilization up until 2003... pictures, instant messages, and tweets all add to this."

Communicative informatics is the formation of online audiences by people's everyday private and public communication in a continuously feedback loop between users and organizations through corporate information systems that store and analyze audience communication. Public communication is the expression of ideas, messages, or images to many people. Goodnight (1982) defines the private discursive as informal everyday communication where individuals discuss personal events and topics that are ephemeral and lack preservation. For the first time in history, the private discursive, although mediated, is accessed, stored, and analyzed by corporations. The transitory nature of everyday discourse is transformed to one that is lasting and preserved foremost by corporate and government interests. Thus, a more complex digitized two-way feedback loop alters post-mass media audiences as a commodity.

Traditional one-way mass media has been a colonizer of audience "free time" which is sold to advertisers by media corporations (Jhally, 1990, p. 183-184). This traditional mass media audience was conceptualized by Smythe (2006, pp. 233-238) as a "commodity audience." In a post-mass media society, the commodity audience with rapid online two-way communication is constructed differently. Mass media communication is a one-way communication to publics and there is a need to gather public opinion using opinion polls and surveys. These surveys are limited to a small number of people in the sample and entail a lag time before the data can be analyzed. In contrast, corporations in post-mass media society dig into their databases and analyze public opinion using people's online communication with family, friends, and communities in real-time. By data mining people's online communication, corporations have an entry into audience communication and its meanings, which provides vital knowledge for devising persuasive messages influencing people's opinions and behaviors. With this shift, we must closely inspect the implications of allowing corporations to own, analyze, and monetize our private and public communication which together, as Hauser (2007) contends, encompasses our society's formal and informal communication patterns that have an impact on democracy and our public common for communication activities. We define a public common as space where citizens can freely engage in public communication.

\section{Three Discursive Spheres of Communicative Informatics}

To better understand the monitoring of online private and public communication, we outline how three major discursive spheres work together to control online communication openness and its consequences for post-mass media society's public common. These spheres of discourse, which combine human communication and information systems, are depicted in Figure 1.

Sphere 1 (database information systems) is where data information systems facilitate the technological means of social media to operate, as well as to collect, store, and analyze user data. Sphere 2 (human computer interaction) is the interface between users and technology devices. If Spheres 1 and 2 work to provide a high enough level of usability and positive user-experience with technology interfaces, then Sphere 3 (active audiences) can be enacted and human-to-human 
communication can occur in the private and public rhetorical speech situations that are vital to democracy.

\section{Discursive Spheres of Communicative Informatics}

\begin{tabular}{|l|l|}
\hline Sphere 3 & $\begin{array}{l}\text { Active Audiences } \\
\text { Focus: Communication, Rhetorical, and Web-Based Social Media } \\
\text { Human communication is facilitated and the user experience with the technology is easy. Human } \\
\text { interaction is primary and in the foreground. Users become active audience members engaging in } \\
\text { private and public communication. People can use social media to create public commons for } \\
\text { interaction. People primarily are interacting to other people's communication rather than } \\
\text { expending a large amount of cognitive effort and physical energy understanding how to use the } \\
\text { technology's interface as in Sphere 2. If Sphere } 2 \text { or } 3 \text { is interrupted, then the human-to-human } \\
\text { communication in Sphere } 3 \text { is disrupted and lost. }\end{array}$ \\
\hline Sphere 2 & $\begin{array}{l}\text { Human Computer Interaction } \\
\text { Focus: Interface Between User and Technology Device } \\
\text { The technology is in the foreground for the user, who needs to learn how to use the interface to } \\
\text { create, call forth, and manage the input and output of data into information systems' databases. } \\
\text { There is not an immediate sense of social interaction with another person. It is the user interacting } \\
\text { with the technology. People must master Sphere } 2 \text { to engage in Sphere 3. }\end{array}$ \\
$\begin{array}{l}\text { Database \& Information Systems } \\
\text { Focus: Computer Programs, Algorithms, and Data Management } \\
\text { People search and access information from databases while placing personal information and } \\
\text { communication on social media systems. User data are collected, stored, and analyzed by social } \\
\text { media corporations. Here the analysis of user data from Spheres } 2 \text { and } 3 \text { is carried out by } \\
\text { organizations, businesses, and governments. }\end{array}$ \\
Sphere 1
\end{tabular}

Figure 1: Three spheres of communicative informatics

\subsection{Sphere 1: Database Information Systems: Databases, Algorithms, and Feedback Loops}

The ownership of online personal communication filtered through corporate databases is a grey area from a legal standpoint. People provide corporations with personal demographic information, purchase information, personal dialogues, and opinions. The information gathered in Spheres 2 and 3 is stored in databases in Sphere 1, where it is often invisible to users (see Figure 2). Woo (2006) posits that the new concept of privacy in the information age is the right to control one's personal information. More data inquiry is needed to address how the immediate and unlimited access to personal and public information by corporations confounds our understanding of the right to control our personal information and how various communication campaigns (marketing, political, and social advocacy), public opinion analysis, and persuasion work in a post-mass media age.

The Internet changes mediated communication feedback loops. Private online communication is fed into corporate databases from which software programs and algorithms are used to extract and analyze user data for symbolic meaning patterns. This changes the one-way process of mass media communication to a two-way process using the Internet as a conduit for feedback loops that facilitate analysis of audience texts. The new mode of feedback provides an unprecedented window into audience attitudes and behaviors, the raw materials needed to influence consumers with marketing campaigns and persuade citizens with political advocacy messages. As a result, there is a concern about the impact of corporate ownership of information systems (specifically with social media) on privacy, democracy, and the public common.

In the next section, we provide a fuller inspection of how Sphere 2 (human computer interaction) holds a dialectical tension. Social media companies must promote ease-of-use to smooth the progress of user interactions and increase the collection of data; however, ease-of-use is not a priority for companies if it will result in privacy settings that could diminish data collection. 


\section{Discursive Spheres of Communicative Informatics}

\begin{tabular}{|c|c|c|c|}
\hline & & User Discourse for Analysis & $\begin{array}{c}\text { Data to Sphere } 1 \text { for } \\
\text { analysis }\end{array}$ \\
\hline Sphere 3 & $\begin{array}{l}\text { Active Audiences } \\
\text { Focus: Communication, } \\
\text { Rhetorical, and Web- } \\
\text { Based Social Media }\end{array}$ & $\begin{array}{l}>\text { Unstructured text } \\
\text { - Sentiment analysis } \\
\text { - Contextual word analysis }\end{array}$ & \\
\hline Sphere 2 & $\begin{array}{l}\text { Human Computer } \\
\text { Interaction } \\
\text { Focus: Interface } \\
\text { Between User and } \\
\text { Technology Device }\end{array}$ & $\begin{array}{l}>\text { Click path behavior } \\
>\text { Keyword search } \\
>\text { Tagging } \\
>\text { User profile } \\
\text { - Settings } \\
\text { - Locations } \\
\text { - Demographics } \\
\text { - Friends and connections }\end{array}$ & \\
\hline Sphere 1 & $\begin{array}{l}\text { Database \& } \\
\text { Information Systems } \\
\text { Focus: Computer } \\
\text { Programs, Algorithms, } \\
\text { and Data Management }\end{array}$ & $\begin{array}{l}\text { O User behaviors, locations, } \\
\text { demographics, texts, and } \\
\text { connections analyzed for } \\
\text { marketing, business intelligence, } \\
\text { and security }\end{array}$ & $\begin{array}{l}\text { Post-Mass Media } \\
\text { Ceedback Loop to } \\
\text { Corporate Databases }\end{array}$ \\
\hline
\end{tabular}

Figure 2. Feedback Loops. This figure illustrates the types of communication, including behaviors, that are captured in Spheres 2 and 3 to be fed back to Sphere 1 for surveillance, analysis, and commoditization. The data are in a continuous loop with information storage and access.

\subsection{Sphere 2: Human Computer Interaction}

User data is a central commodity of the Internet (Beer \& Burrows, 2007; Fuchs, 2009) but what actions and tasks are allowed by a social media is under the control of corporate owners who can filter information to and from users. User profiles, as a commodity, increase a social media's value when more information is gathered on company databases. Profiles build online identities and provide demographic information, including geographic locations, demographics, settings, and friend connections. Identity construction and creativity are important motivational factors for using social networks such as MySpace and Facebook (Gallant, Boone, \& Heap, 2007); thus, people are attitudinally amenable to freely give their information to corporations. Additionally, a person can supplement his or her identity construction with tags, RSS, and mobile tracking, which all increase information about user behaviors, habits, likes, and dislikes. Identity is complicated online because persistence of web-based communication extends the time frame of the speech act; and identity is searchable, can be replicated, and can be seen by invisible audiences (boyd, 2007). Web-based media companies need the masses to speak as much as possible in order to grow and increase profitability.

The interface, or the point of interaction between user and computerized technology, is a major component in the field of human computer interaction, which promotes theories and practices to design user-friendly technologies. Thus, in order to raise their market value, for-profit social media corporations must design human computer interactions to increase user information input into their databases. Although scholars have stated that the general direction of technology development and change gives more control to the user (Cover, 2006; Shaw, Hamm, \& Knott, 2000), this is, in part, an illusion of user-control. User-control in social media simply provides more opportunities for users to give more information to corporations. More pointedly, social media privacy settings, which 
can decrease information sharing and communication activities, may be designed to provide less user-control.

\subsubsection{User Profile Privacy - A Contradiction for Ease-of-Use}

Making privacy settings visible to users is not to the advantage of social networking sites that depend on gathering user-information as a commodity. As shown in the privacy settings located in Sphere 2, social networks sites have default privacy settings that favor information sharing. To stop information sharing, users must physically change their user-profile privacy settings. Even though socially responsible information systems must be easy to use and transparent in how a user's personal data is being used, stored, and transmitted (Fuchs \& Obrist, 2010), the usability and information architecture paths to privacy settings can be difficult to understand. The comprehension of website privacy policies and the ability to configure privacy settings by users have been found to be low, even among computer-literate people or young people (Marwick, Murgia-Diaz, \& Palfrey, 2010; Proctor \& Vu, 2007). These claims of obfuscation of privacy bear out in the lens of usability and human computer interaction in Sphere 2. Not only are the meanings of individual privacy settings confusing for users but, as of June 2010, Facebook had 50 privacy settings with more than 170 options (Marks, 2010). Further, Collins (2010) reports that Facebook privacy settings are scattered throughout the website and that privacy settings can be conflicting, which leads Facebook to automatically choose the least restrictive privacy setting for users.

The popular press frames Facebook as constantly seeking to subvert privacy by changing its policies and resetting user-profile privacy setting controls back to sharing information with other users and business partners. The goal of limiting privacy settings by Facebook is to monetize user information with data mining for targeted marketing (Stone, 2010). Dvorak (2010) points out that "...Facebook consistently changes the way it operates and constantly resets the privacy settings of the users to nil, as in NO PRIVACY." Facebook makes it difficult for average users to find and change privacy setting to shield personal data (Lyons, 2010).

The dialectical dance of privacy settings in social media is a new way to have power over people without their conscious consent. The legal liability is placed on individual users to change their settings every time a social network changes its user interface or privacy policies. Placing this responsibility on the user philosophically fits well in an individualized western society, such as the United States, where, ideologically, personal choice should trump social, corporate, and government control. Yet, every time privacy settings are changed by a site's owner, the original privacy a user has chosen is taken away. Moreover, as this dialectic continues, site owners make changing privacy settings more difficult and confusing.

Emerging empirical evidence suggests that the uses and gratification that people gain from the use of social media results in a lax attitude, which outweighs or even ignores any potential risks to personal privacy concerns (Debatin et al., 2009). Additionally, default setting of all software, including web-based, are a social welfare concern (Shah \& Kesan, 2008). Nascent, research suggests that people with lower levels of income and education are less likely to change user default settings (Shah \& Sandvig, 2008). Without privacy settings being explicit and easy to use, individuals could expose usually held private activity like dieting and sexual behavior to Google searches. "Users of fitness and calorie tracker Fitbit may need to be more careful when creating a profile on the site. The sexual activity of many of the users of the company's tracker and online platform can be found in Google Search results, meaning that these users' profiles are public and searchable" (Rao, 2011).

Another user setting, mostly affecting mobile computing, is location awareness. Smart phones applications, such as restaurant finder Yelp and friend-finder Four Square, log locations and movements of users. As computing becomes more ubiquitous and entwined in everyday life, user data on personal and public communication, user consumption behaviors, and physical movements with geo-tagging and geographic locators, will increase user-information in corporate databases. Upon analysis, social media companies know users' physical movements, consumption patterns, and with whom people meet offline. Overall, users have a choice to either become hyper-conscious 
of checking and managing privacy settings or ignore what the company is doing with these settings to increase data capture in Spheres 1 and 2 of communicative informatics. Since social media use is increasing, the unintuitive and hard-to-use privacy settings have not affected usage. This is counter to the major tenets of usability research. For example, having clear information design that facilitates high levels of usability promotes ease-of-use and trust in a website and in its owner (Gallant, Irizarry, and Kreps, 2007). For a broad selection of audiences, the uses and gratifications of social media outweigh the potential distrust in the obscuring of privacy setting tasks. Sphere 3 brings rhetorical communication and the active audience into being online as well as the potential for public commons.

\subsection{Sphere 3: Rhetoric and The Active Audience - Online Public Commons}

Audience-centered communication in the age of traditional mass media provided constricted alternatives for public communication due to one-way communication in which media broadcasting did not allow audience interaction and diminished true public space where community members could interact (Goodnight, 1987, p. 429). In contrast, social media give audiences spaces for interaction and a platform for rhetorical invention - a key ingredient of persuasion and the democratic processes needed for communication in a public common.

Rhetoric, at its basis, is a theory of "public speech" that recognizes the persuasive effects of context upon a speech situation (Arnold, 1992). "Rhetoric may be defined as that discipline which deploys the spoken or the written word to affect an evolution in the knowledge, opinion, or attitude of an audience" (Purdie, 2003, p. 1142). Rhetoric is any attempt to influence others with words or images.

The Internet, as a rhetorical context, provides all publics the chance to form public opinion, respond to events, and challenge elite messages (Hauser, 2007). Rhetorical action with its hallmark of the engaged audience has become more active online through "reading, shopping, voting, playing, researching, writing, and chatting" (Livingstone, 2004, p. 76) and can establish public commons, a rhetorical speech situation that is a vital component of democracy.

Hauser (2007) notes that rhetorical speech situations have three basic types of publics: everyday, ${ }^{1}$ measured $^{2}$ (opinion polls), and deliberative. ${ }^{3}$ As a mainstay of public debate and democracy, deliberative communication is defined by people auguring for or against a course of action (Hauser, 2007). Everyday and measured communication both affect deliberative communication as people advance public arguments (Hauser, 2007). All three forms of communication (everyday, measured, and deliberative) exist on the Internet and influence public debate and democracy (Hauser, 2007).

Hauser's (2007) view that the Internet has changed the "formation and expression of public opinion" (p. 338) is widely accepted but we disagree with his statement that the "Internet is not controlled by corporate interests" (p. 338). With Internet monitoring techniques and post-mass media feedback loops, corporations have unprecedented access and control over private and public communication. Understanding online communication must focus on the symbolic complexity of social media (Livingstone, 2006). To this end, we discuss how the centuries-old concept of audience as a rhetorical process is present in post-mass media with four propositions.

\section{The Audience and Four Propositions}

In ancient Athens, the audience often had an active role in legislative, judicial, and ceremonial events. In the direct democratic periods, male citizens made legislative decisions on taxes, spend-

\footnotetext{
${ }^{1}$ Everyday or vernacular communication of the ordinary citizen upholds social bonds and is mainly between family, friends and acquaintances, whose interaction influences public communication. Ordinary citizen vernacular is often missed in monitoring of traditional methods of public opinion measurement (Hauser, 2007).

${ }^{2}$ Measured communication or public opinion polls have been a mainstay for how corporations, politicians, and governments gauge audience sentiment in order to construct persuasive messages that shape public policies and consumer consumption patterns.

${ }^{3}$ Deliberative communication is defined by people auguring for or against a course of action (Hauser, 2007).
} 
ing, war, or peace through rhetorical action. Any free male citizen could speak, ask questions, debate issues, or shout down a speaker (Boone, 2004; Kennedy, 1963). Juries, composed of several hundred male citizens, heard arguments in a single day and then rendered their verdicts based on majority vote. A speaker would use a variety of proofs (pisteis) to appeal to the audience. Aristotle (1960) stated: "For we have seen that persuasion can be effected only (1) by working on the emotions of the audience (pathos), or (2) by giving the audience the right impression of the speaker's character (ethos), or (3) by convincing them all with proof (logos)" (Rhetoric, 1403b). Speakers would not be effective unless they adapted their arguments to the audience based on proofs. With user data, social media corporations have increased insights into the proofs (pathos, ethos, and logos) that can persuade audiences and impact public debate. Four propositions are presented to clarify how online audience activity is encouraged by and imperative to corporate interests; how audience creativity can create, accept, or reject messages; how the online audience is monitored; and how the online rhetorical situation can produce or inhibit public commons.

\subsection{Proposition 1: The Audience is Active}

The Internet provides an active audience with a communicative platform similar to an ancient polis where the government is ruled by an active citizenship; however, in post-mass media society corporations control important web-based public communication spaces that can influence democratic processes. As discussed earlier, online profiles are a central commodity of the Internet. Social media profiles and online corporate representations signify character (ethos), a major rhetorical proof. Individuals and corporations can use their ethos to persuade online.

Social media companies promote online political communication. Fuchs (2011) points out that corporations such as Google have large amounts of money which helps to influence political power (Fuchs, 2011). For instance, about three-quarters (74\%) of U.S. Internet users went online during the 2008 U.S. election to participate in or get campaign news and information. This represents $55 \%$ of the entire U.S. adult population, and marks the first time the Pew Internet \& American Life Project have found that more than one-half of the American voting-age population used the Internet to connect to the political process during the election cycle (Smith, 2009). Scherer \& Newton-Small (2008) state: "For millions of Americans, the Internet has turned presidential politics into a fully interactive event, a chance to give money with mouse clicks and to volunteer virtually from miles away."

More recently and perhaps more telling of social media's control and filtering of public debate is President Obama's Twitter Town Hall, jointly held and sponsored by Twitter and The Whitehouse on July 6, 2011. The process used to choose questions from Twitter posts to be answered by the President is representative of a post-mass media process reliant on proprietary algorithms for corporate analysis of user-data. This is different than a traditional mediated town hall because active audience members do not have to be in the same physical space and corporations act as information gatekeepers. Twitter's CEO Jack Dorsey read 18 Tweets for the President to answer (Jackson, 2011). In this example, the process of choosing questions rested largely on Twitter database algorithms. "For just over an hour, the president answered questions submitted by the public through Twitter. The questions were selected by Twitter staff, who relied in part on an algorithm that measured which of thousands of proposed questions were most popular" (Meckler, 2011). A reported 169,395 tweets were reportedly sent (Dunn, 2011). In April 2011, Facebook hosted a town hall meeting with President Obama held at the corporation's Palo Alto, CA, headquarters (Weisbrod, 2011). The event was moderated by Facebook CEO Mark Zuckerberg. A small audience in the room asked the President questions while the event was live web-casted over Facebook to its users. YouTube also has been part of the social media's participation in political communication. In January, two days after his State of the Union address, President Obama answered YouTube users' questions about his speech (Weisbrod, 2011).

As seen above, social media owned by private companies is being infused into public debate with the potential for them to act as gatekeepers. Unlike traditional mass media and journalism, corporate social media have no professional tenets for reporting public communication. In fact, 
reporting public information is not the main enterprise of social media companies. For these companies to grow and compete against each other for market share, they must drive audience activity in as many aspects of people's lives as possible. This includes people's roles as buyers, reviewers, and fans on recommendation and review websites (Yelp, Urbanspoon, Citysearch, CNET, and Epinions), which span interests such as travel, restaurants, and consumer products. As users consume online and offline, they write impressions about and vote on the products and services. The active audience is an online commodity due to the creation of online audience content that is analyzed for corporate economic advantage (Fuchs, 2011).

Online audiences are influencing the public rhetoric of the consumption of goods. In turn, social media companies provide the platform for the communication and have user data to draw on as a commodity for advertising. Social media corporations continue to encourage more audience engagement with new ways users can interact and display information. By providing more webbased applications, especially those that are mobile, companies provide an incentive for people to continuously supply data. The companies then reap increased economic benefits through advertising to users (Fuchs, 2011). In mobile computing, users provide data on their geographic locations in exchange for learning more about their immediate environment in the way of maps, dining recommendations, finding friends, and historic landmarks. An example of a geographic location tools friend finder is Four Square, which allows members to use mobile phones to locate friends and view their recent activity. Overall, active audience members in the roles of consumers, political actors, citizens, friends, colleagues, and family members provide social media corporations with large and increasing amounts of insights into user attitudes, behaviors, and consumption patterns.

\subsection{Proposition 2: The Audience is Creative}

Audiences creatively structure information in the process of rhetorical intervention, which is using the tools of symbolic meaning systems such as proofs (pathos, ethos, and logos) to communicate with and influence others. Rhetorical invention, a creative process of developing persuasive messages for audiences, is a core process in online communication (Boone, 2004). The "first act of rhetorical invention is to invent the Self' (Medhurst, 2004, p. 569). Sphere 3 gives rise to the mediated rhetorical invention and is infused with social presence, the awareness of other people. Since people online "have a sense of audience in every mediated conversation, whether on instant messenger or through blog comments" (Marwick \& boyd, 2011, p. 115), the online rhetor is conscious of his or her audience in creating meaningful and persuasive messages as in a traditional rhetorical situation.

More than depositing demographic information in social media databases, people build rhetorical texts that expose attitudes and behaviors to corporate interests. Moreover, the argument strategies that people use with proofs (pathos, ethos, and logos) are readily available to corporate monitoring and analysis. Based on analysis of user communication, corporations can better target persuasive marketing or political messages. Additionally, as corporations filter, analyze, and influence user communication, they become part of the rhetorical invention process by way of the Internet's digitalized post-mass media feedback loop, which continuously links audience communication with corporate databases. For example, $40 \%$ of online advertising allows real time feedback, enabling marketers to buy known audiences (Economist, 2011). "Click to open a web page and an automated auction begins. Firms bid to serve an advertisement, taking into account where it will appear and what they know about the presumed viewer from digital traces he has inadvertently left around the web. The winner serves the advertisement, often customising [sic] it-so you may see more ads for convertible cars on a sunny day. The whole process generally takes some 150 milliseconds, or less than half the blink of an eye" (Economist, 2011).

Ultimately, the audience decides if the speakers (individuals, organizations, or governments) are effective. If an audience is influenced by communication, they can act upon it to affect change in the world (Arnold, 1992). Online rhetorical influence leads people to experience emotions and make actionable judgments (Segal, 2009). Online audiences through rhetorical creation can support, resist, rearrange, or ridicule any messages. They can take corporate message sent out to 
them in Sphere 2 and bring the corporate communication into Sphere 3, where audiences debate, discuss, create messages, construct identities, or take action. These rhetorical actions can be positive, neutral, negative, profound, or superficial; thus, marketing and political messages can be accepted or rejected. The potential for audiences to carry out communication that has an impact on social, economic, and political areas begets monitoring.

\subsection{Proposition 3: The Audience is Monitored}

While scholars have written about the implications of free labor by online users, there is less emphasis on how the monitoring and analysis of symbolic meaning patterns can equip corporations and governments with insights for persuasive messages without warning to users. The audience has rhetorical freedom with surveillance. Increases in communication freedom leads to less privacy online because more data are available for monitoring. Many disciplines, such as computer science, psychology, computational linguistics, and pedagogy have devoted significant research efforts to studying how users classify information online (Panke \& Gaiser, 2009). User-data analysis is employed by corporations mostly to sell advertising. Global online advertising is an economic powerhouse and MagnaGlobal (2011) reports it will account for $\$ 70.9$ billion during 2011 and $\$ 117.5$ billion by 2016 .

The central corporate surveillance threat on the Internet is online advertising which accumulates user's personal data to sell to advertisers (Fuchs, 2011). Online advertising promotes ideological messages by presenting limited views of reality to audiences (Fuchs, 2011). User analysis is comprised from five processes: tagging, search, ${ }^{4}$ contextualization, ${ }^{5}$ semantic analysis, ${ }^{6}$ and behavioral advertising. ${ }^{7}$ The latter four analysis types are indiscernible to online technology users; automated database-driven analysis techniques are regularly hidden from users in contrast to tagging activity for which users actively build topical areas and lists.

A critical dilemma with these four discrete analysis types (search, contextualization, semantic analysis, and behavioral tracking) is that users can be unaware of these processes performed on their online communication activities. This brings about an illusion of free online communication that is often unknowingly paid for with users' private and public communication that is analyzed by corporations who can develop persuasive messages based on user sentiments and behaviors. The data-rich push and pull feedback loop between audience members and social media corporations is shown in Figure 3. As computer algorithms gain more accuracy in analyzing online talk and texts, the predictive and representational power of surveillance and intelligence on people's public opinion can increase.

Besides monitoring for commoditization, social media is a platform for tensions in geopolitics. Globally, governments, often with help from corporate technology partners, impose restrictions on Internet communication in many ways such as web blocking, censorship, denial of access, infrastructure control, attacks on exile-run sites, malware attacks, state cybercrime, and Internet kill switches (O'Brien, 2011). Rhetors through social media have brought visions of war-torn countries and revolutions in countries such as Tunisia, Egypt, and Libya to web-based and traditional media

\footnotetext{
${ }^{4}$ Search advertising is based on the search terms or phrases that people put into search boxes. This is typical of Google search. Users receive search results while simultaneously their queries are automatically logged into corporate databases and attached to users' profiles and IP addresses.

${ }^{5}$ Contextual advertising is an analysis of specific words in a text. Words appearing in an email, chat discussion, or social media message will be analyzed by an algorithm which deduces what products and their advertisements most closely match user interests based on words in a text. Advertisements are served-up and displayed on users screens. For instance, if a message has the word shoes in it, advertisements for shoes will most likely appear on user screens.

${ }^{6}$ Semantic analysis, still in its early development stages, applies an algorithm to perform an automated content analysis of text, which helps to determine topical meaning patterns in data. This is different than analyzing one word like in contextual advertising. Here algorithms are built to distinguish topical sentiments of positive and negative valence in user-generated unstructured (not tagged) text. This process seeks to identify people's attitudes and opinions, which are vital to effective persuasion campaigns.

7 Behavioral advertising is based on tracking users' behaviors as they move through and across websites. Based on websites people visit, inferences are made on users' likely consumption patterns.
} 
audiences (Etling et al., 2010; Gaystolberg, 2011). During the Iranian student protests in 2009, a 27-year-old student protester was shot and died in the street. A viral Internet video of Neda Agha Soltan's death symbolized Iranian protests (see, Barnett, 2009; Fathi, 2009). The video was used as proof in continued protest, even though Iran continuously blocked Internet connections.

Given the networked and non-linear nature of the Internet, users often get around government surveillance and blockages, freeing themselves temporarily from limitations. Far more than a passive media audience, an active and creative audience has the potential to subvert control. Breaking through constraints with the use of communication is a hallmark of rhetoric, which recognizes the potential of constitutive power in which communicative action can counter-balance domineering power (Goodnight, 1987).

\subsection{Proposition 4: The Mediated Rhetorical Situation Creates the Public Common}

Social media bring about participatory democracy through communicative action (Carty, 2010) and create a public common for citizens. As people consume and create online content, they actively identifying audiences and formulate arguments (Beach \& Doerr-Stevens, 2009, p. 467; Sheridan \& Hart-David, 2008). If people employ audience identification strategies and argument formation, there is a keen awareness of online audience presence and the potential for deliberative communication and a public common, a hallmark of the democratic process. Deliberative democracy can occur online (see, Maynor, 2009; Schlosberg, Zavestoski, \& Shulman, 2007; Vromen, 2008) and with any deliberative communication, there must be an accounting for power relationships (Dahlberg, 2007). Deliberative communication is affected by how open and free communication is in a society. Social media platforms can affect filtering of communication and the degree of communication openness in a public common. See Figure 3.

\section{Openness of a Social Media Platform as a Public Common}

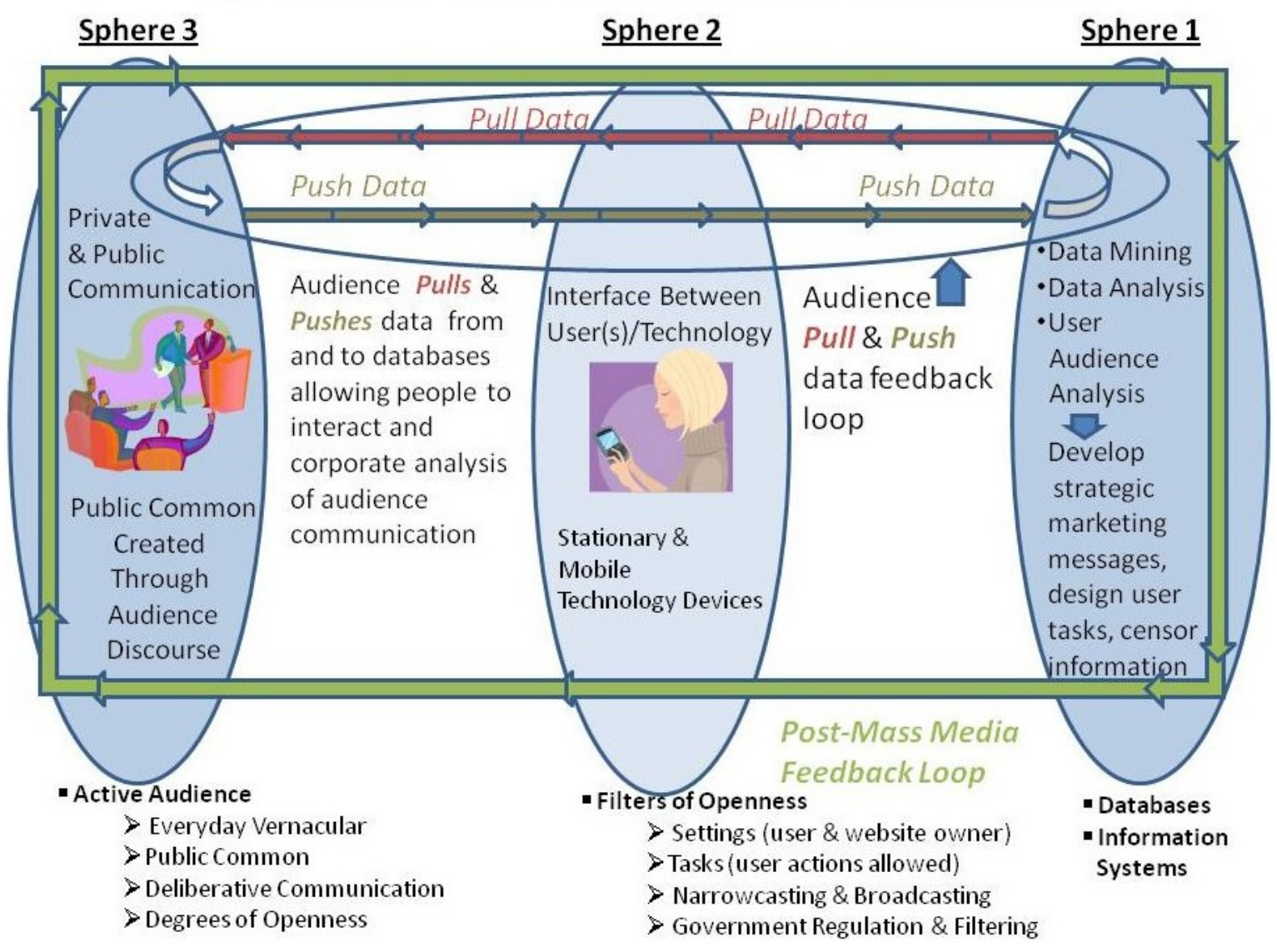


Figure 3. Openness of social media platform as a public common. The complexity of post-mass media is depicted through: the increased feedback loops of pull and push data; user data collection and analysis in databases; message generation by people and corporations; and how open or limited communication can be based on tasks allowed by a technological design.

The degree of communication openness in social media is used not only for business strategy but also for political and governmental power, which sometimes leads to control and shutting down online public communication. Political censorship online with the help of social media companies diminishes free access to online communication. Corporation such as Google, Yahoo!, and Microsoft bend to pressures of governments to monitor and filter communication in order to conduct business within certain countries. For instance in order to continue conducting business in China, Google cedes to China's demand to censor Internet searches to comply with government sanctioned websites (Hoffman, 2010). A Paris-based humanitarian group, Reporters Without Borders, has criticized Google, Yahoo!, and Microsoft, for censoring Internet searches and communication for governments such as China and Egypt (MacMillan, 2009). The censorship extends beyond governmental requests. Yahoo! and Google are increasingly censoring Internet searches and website linking for entertainment industries (TorrentFreak, 2011). Censorship is part of social media business practices. Governments also repress Internet activity by shutting down Internet access. This was seen when the Egyptian government of Hosni Mubarak shut down ISPs to prevent the continued organization of protest rallies and to prevent news of protests getting out of the country (Mitra, 2011).

Some companies battle with governments who seek information to combat crime. The tension between corporate social media control over user data and privacy is exacerbated when governmental agencies ask Internet companies to provide user data to monitor crimes. Such is the case with sex trade and slavery. Facebook and Google have joined forces legally against the French government. The French group Association of Internet Community Services, established in 2007 by AOL, Dailymotion, Google, and Yahoo has sought to fight the French government's regulations on the retention of users' personal data such as passwords, e-mails, addresses, and telephone numbers (Whitney, 2011). Social media corporations resist attempts by governments to have access to user data for criminal investigations. When they can battle for user privacy against governments, corporations frame themselves as protectors of public privacy. Corporations need to protect data privacy only for economic gains. When people perceive technologies as untrustworthy, they are less likely to use them (Gallant, Irizarry, and Kreps, 2007). If users believe the use of a social media can be used in police investigations, they might be less willing to use the technology.

The dialectical tension between censorship and open Internet access will continue to have implications for public communication. Collecting and storing user data for economic gain while suppressing the use of the same data for a public potential good such as criminal investigations, places interactive media companies at the core of an Internet age's dilemma, which is who owns the online public common. When social media companies provide a "public common," the active audience's communication is, at least in part, owned and filtered by the corporations. When Internet companies shut down access to parts of the Internet for certain countries, people do not have a full range of rhetorical proofs to engage in open communication. Thus, online audiences can draw only on information supplied through Internet censorship based on political or business goals.

\section{Conclusion}

Social media are a platform for personal and public rhetoric where individuals, groups, corporations, governments and social movements attempt to influence people and the public. The use of social media shows social bonds; whether, people are in agreement or dissention such as in political communication, product uses, or health advocacy communication. In social media people talk about everything from everyday events to persuasion about personal and public matters of importance. Communicative informatics as a rhetorical framework examines how three discursive spheres (database and information systems, human computer interaction, and active audiences) 
operate in post-mass media society. Meanings are not determined by technology. Rather, it is the active audience in communication with its members and communication filtered by social media companies that use, expand, and sometimes change, the original intent of messages.

User-generated content can be monitored as never before in real-time by corporations and governments. The private and public information learned from online audiences holds potential for promoting open debate and understanding in society and also manipulation and surveillance of public communication filtered through organizational databases. It is a tension pitting a utopian open communication model against a dystopian perspective, which warns of surveillance and privacy invasion. In an open model, people produce culture online in the free flow of user-generated texts. Contrasting this is the enclosure of the public's information in corporate databases where dystopian invasion of privacy and social surveillance are realized in the tracking, storage, and analysis of socially-produced online communication. Four propositions (the audience is active; the audience is creative; the audience is monitored; and the mediated rhetorical situation creates the public common) are presented to clarify how online audience activity is encouraged by and imperative to corporate interests; how audience creativity can create, accept, or reject messages; how the online audience is monitored; and how the online rhetorical situation can produce or inhibit public commons.

We need continued examination of corporate and government trends that promote or impinge on online communication freedom essential in identifying democratic freedoms in a post-mass media era. More specifically, research is needed in this area with an eye on how post-mass media can influence deliberative communication and have an impact on the public common to better understand how freedom of speech in post-mass media can be a commoditized and controlled for corporate and political power. This is important in an era where, as Fuchs (2011) points out, corporations such as Google have large amounts of money which helps to influence political power (Fuchs, 2011). This process is indicative of what Fuchs (2009) describes as the well-established "social struggles over the public or private character of information" (p. 80).

Questions for the future might look to how the tensions between web-based speech and its surveillance can affect individual privacy, crime fighting, public debate, and public advocacy. Future research could empirically examine if online communication has shifted the western concept of privacy. For this to be undertaken, research would first need to investigate people's awareness level of online monitoring. Once people are aware, what is their view of being monitored online? Secondly, whether or not social media users care if their communication is under surveillance by organizations and governments should be determined. Do people want the right to be left alone as traditional privacy laws dictate or, as Woo (2006) theorizes, is the new definition of privacy the right to be anonymous? Other future research could examine what social media systems have higher levels of creativity, higher levels of discourse, or different levels of influence. What rhetorical techniques are used by different types of online audiences? A rhetorical viewpoint would examine the arguments, emotional terms, the credibility of different rhetors, and the responses of different audiences who use social media.

\section{References}

Aibar, E. (2010). A critical analysis of information society conceptualizations from an STS point of view. Triple-C: Cognition, Communication, Cooperation, 8(2), 177-182.

Aristotle. (1960). The rhetoric of Aristotle. (L. Cooper, Trans.). Englewood Cliffs, NY: Prentice Hall.

Arnold, C. C. (1992). Oral rhetoric, rhetoric, and literature. Philosophy \& Rhetoric, Supplement, 25, 48-67.

Barnett, R. (2009). 'Shot Girl' In Video Named On Mousavi Site. Sky News. Retrieved on July 27, 2011 from http://news.sky.com/skynews/Home/World-News/Neda-Woman-Allegedly-Killed-In-Iran-Protests-Named-As-NedaAgha-Soltan-On-Mousavi-Facebook-Page/Article/200906415314153

Beach, R., \& Doerr-Stevens, C. (2009). Learning argument practices through online role-play. Toward a rhetoric of significance and transformation. Journal of Adolescent \& Adult Literacy, 52(6), 460-468.

Beer, D., \& Burrows, R. (2007). Sociology and, of and in Web 2.0: Some Initial Considerations. Sociological Research Online, 12(5), Retrieved on March 27, 2011 from http://www.socresonline.org.uk/12/5/17.html

Benkler, Y. (2000) From consumers to users: Shifting the deeper structures of regulation toward sustainable commons and user access. Federal Communications Law Journal, 52(3), 561- 579. 
Benkler, Y. (2006). The wealth of networks: How social production transforms markets and freedom. New Haven, CT: Yale University Press.

Boone, G. (2004). How the rhetorical tradition informs web design, information architecture and usability. International Journal of the Humanities, 2(3), 2223-2228.

Boone, G. M., \& Gallant, L. M. (2007, July). Active, creative and monitored: The audience transformed in online media. International Association for Media and Communication Research. Conference conducted at the meeting of IAMCR in association with UNESCO, Paris.

boyd, danah. (2007). Why youth (heart) social network sites: The role of networked publics in teenage social life. In D. Buckingham (Eds.), Youth, identity, and digital media volume. Cambridge, MA: MIT Press.

Carty, V. (2010). New information communication technologies and grassroots mobilization. Information, Communication \& Society, 13(2), 155-173.

comScore. (2010, September 9). Facebook inches past Google for Web users' minutes. Retrieved on September 10,2010 from http://www.google.com/hostednews/ap/article/ALeqM5jxi8CbGDQ2gGetuc2d5Nz-RoK76gD914QAH82

Collins, J. C. (2010). Fortify your Facebook settings: Don't let the window into your personal life sully your professional reputation. Journal of Accountancy, June, 42-44.

Cover, R. (2006). Audience inter/active: Interactive media, narrative control and reconceiving audience history. New Media \& Society, 8(1), 139-158.

Dahlberg, L. (2007). The Internet, deliberative democracy, and power: Radicalizing the public sphere. International Journal of Media and Cultural Politics, 3(1): 47-64.

Debatin, B., Lovejoy, J. P., Horn, A., \& Hughes, B. N. (2009). Facebook and online privacy: Attitudes, behaviors, and unintended consequences. Journal of Computer-Mediated Communication, 15(1), 83-108.

Deuze, M. (2006). Participation, remediation, bricolage: Considering principal components of a digital culture. The Information Society, 22(2), 67-75.

Dunn, M. (2011). Recap of Obama's Twitter town hall meeting. Digital trends. Retrieved on July 7, 2011 from http://www.digitaltrends.com/social-media/recap-of-obamas-twitter-town-hall-meeting/

Dvorak, J. C. (2010). Why Facebook privacy settings don't matter. PC Magazine, 29(7), 1. Retrieved on March 27,2011 from http://www.pcmag.com/article2/0,2817,2365866,00.asp

Economist. (2011, May 5). Mad Men are watching you: How real-time bidding will affect media companies. Retrieved on July 27, 2011 from http://www.economist.com/node/18651104

Etling, B., Kelly, J., Faris, R., \& Palfrey, J. (2010). Mapping the Arabic blogosphere: Politics and dissent online. New Media \& Society, 12(8), 1225-1243.

Fathi, N. (2009). In a death seen around the world, a symbol of Iranian protests. New York Times. Retrieved on July 27, 2011 from http://www.nytimes.com/2009/06/23/world/middleeast/23neda.html

Fuchs, C. (2009). Information and communication technologies \& society: a contribution to the critique of the political economy of the Internet. European Journal of Communication, 24 (1), 69-87.

Fuchs, C. (2011). Web 2.0, prosumption, and surveillance. Surveillance \& Society, 8(3), 288-309.

Fuchs, C. \& Obrist, M. (2010). HCl and society: towards a typology of universal design principles. International Journal of Human-Computer Interaction, 26(6), 638-658.

Gallant, L.M., Irizarry, C., Boone, G.M., \& Ruiz-Gordon, B. (2010). Spanish content on hospital websites: An analysis of U.S.hospitals' in concentrated Latino communities. Journal of Computer-Mediated Communication, $15(4), 552-574$.

Gallant, L.M., Irizarry, C., \& Boone, G.M. (2008). Chapter XV: Exploring the Technology Adoption Needs of Patients Using E-Health. In Wilson, E. V. (Ed.), Patient-Centered E-Health, (pp. 201-216). Hershey, PA: Information Science Reference (IGI Global).

Gallant, L. M., Boone, G. M., \& Heap, A. (2007). Five heuristics for evaluating Web-based communities. First Monday, 12(3). Retrieved September 26, 2010 from http://firstmonday.org/article/view/1626/1541

Gallant, L.M., Irizarry, C., \& Kreps, G. (2007). User-centric hospital websites: A case for trust and personalization. e-Service Journal, 5(2), 5-26.

Gallant, L. M. (2006). An ethnography of communication approach to mobile product testing. Personal and Ubiquitous Computing, 10(5), 325-332.

Gaystolberg, S. (2011). Shy U.S. intellectual created playbook used in a revolution. New York Times. Retrieved May 1 , 2011 from http://www.nytimes.com/2011/02/17/world/middleeast/17sharp.html? r=2\&hp=\&pagewanted=all

Goodnight, G. T. (1987). Public discourse. Critical Studies in Media Communication, 4, 428-431.

Harrison, T., \& Barthel, B. (2009). Wielding new media in Web 2.0: Exploring the history of engagement with the collaborative construction of media products. New Media and Society, 11(1), 155-178.

Hauser, G. A. (2007). Vernacular discourse and the epistemic dimension of public opinion. Communication Theory, 17(4), 333-339

Herold, D. K. (2010). Imperfect use? ICT provisions and human decisions: An introduction to the special issue on ICT adoption and user choices. Information Society, 26(4), 243-246.

Hoffman, S. (2010). Google caves to China: Halts Hong Kong search redirect. CRN. Retrieved on July 27,2011 from http://www.crn.com/news/applications-os/225701843/google-caves-to-china-halts-hong-kongsearchredirect.htm;jsessionid=up-kQx4ukCQSuYAiSsfrLg ${ }^{* *}$.ecappj03

Jackson, D. (2011). Obama welcomes Twitter to White House. USA Today. Retrieved on July 14, 2011 from http://content.usatoday.com/communities/theoval/post/2011/07/obama-welcomes-twitter-to-whitehouse/1?csp=34news

Jhally, S. (1990). The codes of advertising: Fetishism and the political economy of meaning in the consumer society. New York: Routledge.

Kennedy, G. (1963). The art of persuasion in Greece. Princeton, NJ: Princeton University Press.

Kim, S. T., \& Weaver, D. (2002). Communication research about the internet: A thematic meta-analysis. New Media \& Society, 4(4), 518-538. 
LaRose, R., \& Eastin, M. S. (2004). A social cognitive theory of Internet uses and gratifications: Toward a new model of media attendance. Journal of Broadcasting \& Electronic Media, 48(3), 358-377.

Lessig, L. (2001). The Future of Ideas. New York: Random House.

Lessig, L. (2006). Code 2.0. New York: Basic Books.

Lessig, L. (2005). Free Culture: The Nature and Future of Creativity. New York: Penguin Books.

Lessig, L. (2008). Remix. New York: Penguin.

Livingstone, S. (2004). The challenge of changing audiences: Or, what is the audience researcher to do in the age of the Internet? European Journal of Communication, 19(1), 75-86.

Livingstone, S. (2006). Drawing conclusions from new media research: Reflections and puzzles regarding children's experience of the internet. The Information Society, 22(4), 219-230.

Lyons, D. (2010). The high price of Facebook. Newsweek, 155(21/22), 22. Retrieved on March 27, 2011 from http://www.newsweek.com/2010/05/15/the-high-price-of-facebook.html

MacMillan, D. (2009). Google, Yahoo Criticized Over Foreign Censorship. Bloomberg Businessweek. Retrieved on July 27, 2011, from http://www.businessweek.com/technology/content/mar2009/tc20090312_381922.htm

MagnaGlobal (2011). 2011 advertising forecast. Retrieved on July 27, 2011, from http://www.magnaglobal.com/wpcontent/uploads/downloads/2010/12/2011-MAGNAGLOBAL-Advertising-Forecast-Abbreviated.pdf

Marks, P. (2010). Social networks must heed the human element. New Scientist, 206(2763), 9.

Marwick, A. E., \& boyd, d. (2011). I tweet honestly, I tweet passionately: Twitter users, context collapse, and the imaginedaudience. New Media Society, 13(1), 114-133.

Marwick, A. E., Murgia-Diaz, D. \& Palfrey, J. G. (2010) Youth, privacy and reputation (Literature Review). Berkman Center Research Publication No. 2010-5; Harvard Public Law Working Paper No. 10-29. Retrieved November 2, 2010 from http://ssrn.com/abstract=1588163

Maynor, J. W. (2009). Blogging for democracy: Deliberation, autonomy, and reasonableness in the blogosphere. Critical Review of International Social and Political Philosophy, 12(3), 443-468.

Meckler, L. (2011). Obama Takes Twitter Queries: President Fields Public Questions on Issues Including Economy and Debt Ceiling. The Wall Street Journal. Retrieved on July 7, 2011 from http://online.wsj.com/article/SB10001424052702303544604576430082812040322.html?mod=googlenews wsj

Medhurst, M. J. (2004). Filled with the spirit: Rhetorical invention and Pentecostal tradition. Rhetoric \& Public Affairs, 7(4), $555-572$.

Mitra, K. (2011). 21st Century Revolution. Business Today, 20(5), 119.

Nielsen Company. (2010a). Social networks/blogs now account for one in every four and a half minutes online. Retrieved on June 20, 2010 from http://blog.nielsen.com/nielsenwire/online mobile/social-media-accounts-for-22-percent-of-timeonlinel

Nielsen Company. (2010b). Led by Facebook, Twitter, global time spent on social media sites up $82 \%$ year over year. Retrieved on January 24, 2010 from http://blog.nielsen.com/nielsenwire/global/led-by-facebook-twitter-global-time-spenton-social-media-sites-up-82-year-over-yearl

O'Brien, D. (2011). The 10 tools of online oppressors. CJP: Committee to protect journalists. Retrieved on May 2, 2011 from http://www.cpj.org/reports/2011/05/the-10-tools-of-online-oppressors.php

Panke, S., \& Gaiser, B. (2009). "With my head up in the clouds": Using social tagging to organize knowledge. Journal of Business and Technical Communication, 23(3), 318-349.

Parameswaran, M., \& Whinston, A. B. (2007). Research issues in social computing. Journal of the Association for Information Systems, 8(6), 336-350.

Proctor, R. W., \& Vu, K. (2007). A multimethod approach to examining usability of Web privacy policies and user agents forspecifying privacy preferences. Behavior Research Methods, 38(2), 205-211.

Purdie, D. W. (2003). Classical Greek and Roman rhetoric and the modern audience. Medical Education, 37(12), 11411144.

Qvortrup, L. (2006). Understanding new digital media: Medium theory or complexity theory? European Journal of Communication, 21(3), 345-356.

Rao, L. (2011). Sexual activity tracked by Fitbit shows up in Google search results. Retrieved on July 27, 2011 from http://techcrunch.com/2011/07/03/sexual-activity-tracked-by-fitbit-shows-up-in-google-search-results/

Scherer, M., \& Newton-Small, J. (2008). Why Democrats rule the web. Time. Retrieved on April 22, 2008 from http://www.time.com/time/magazine/article/0,9171,1731879,00.html

Schlosberg, D., Shulman S., \& Zavestoski, S. (2007). Democracy and e-rulemaking: Web-based participation and the potential of deliberation. Journal of Information Technology and Politics, 4(1), 37-55.

Segal, J. Z. (2009). Internet health and the 21st-Century patient: A rhetorical view. Written Communication, 26(4), 351-369.

Siegler, M. (2010). Eric Schmidt: Every 2 days we create as much information as we did up to 2003 tech crunch. Retrieved on April 20, 2011 from http://techcrunch.com/2010/08/04/schmidt-data/

Shah, R. C., \& Kesan, J. P. (2008). Setting online policy with software defaults. Information, Communication \& Society, 11(7), 989-1007.

Shah, R. C., \& Sandvig, C. (2008). Software default as de facto regulation: The case of the wireless internet. Information, Communication \& Society, 11(1), 25-46.

Shaw, D. L., Hamm, B. J., \& Knott, D. L. (2000). Technology change, agenda challenge and social melding: Mass media studies and the four ages of place, class, mass, and space. Journalism Studies, 1(1), 57-79.

Sheridan, D. M., \& Hart-David, W. (2008). Just for fun: Writing and literacy learning as forms of play. Computers and Composition, 25(3), 323-340.

Smith, A. (2009, April 15). The internet's role in campaign 2008. Retrieved April 16, 2009 from http://pewresearch.org/pubs/1192/internet-politics-campaign-2008

Smythe, D. W. (2006). On the audience commodity and its work. In M.G. Durham and D.M. Kellner (Eds.), Media and Cultural Studies Key Works (pp. 230-256). Malden, MA: Blackwell. 
Steers, R. M., Meyer, A. D., \& Sanchez-Runde, C. J. (2008). National culture and the adoption of new technologies. Journal of World Business, 43(3), 255-260.

Stone, B. (2010). Sell your friends. Bloomberg Businessweek; 64-72. Retrieved on March 27, 2011 from http://www.businessweek.com/magazine/content/10_40/b4197064860826.htm

TorrentFreak (2011). Yahoo! Messenger censors FilesTube links. TorrentFreak. Retrieved on July 27, 2011, from http://torrentfreak.com/yahoo-messenger-censors-filestube-links-110329/

Vromen, A. (2008). Building virtual spaces: Young people, participation and the internet. Australian Journal of Political Science, 43(1), 79-97.

Weisbrod, E. (2011). Obama and social media. CNN. Retrieved on July 14, 2011 from http://whitehouse.blogs.cnn.com/2011/07/06/obama-and-social-media/

Whitney, L. (2011, April 6). Net trade group protests French data retention rules. CNET News. Retrieved on March 27, 2011 from http://news.cnet.com/8301-1009 3-20051320-83.html

Woo, J. (2006). The right not to be identified: Privacy and anonymity in the interactive media environment. New Media \& Society, 8(6), 949-967.

\section{About the Authors}

Linda M. Gallant, Ph.D.

is an assistant professor and graduate director in the department of communication studies at Emerson College. Having professional experience in usability and a Ph.D. in communication, Gallant brings a trans-disciplinary background to the burgeoning areas of user-experience design and social media. Specifically, she investigates how new media facilitate human communication by investigating Internet-based technologies as social artifacts. A central interest in her research and teaching is how a technology's design and development (information architecture, usability, and rhetorical strategies) has an impact on its social and cultural uses, especially public communication. She is published in Journal of Computer-Mediated Communication, Personal and Ubiquitous Computing, Qualitative Research Reports in Communication, First Monday, and e-Service Journal.

Gloria M. Boone, Ph.D.

is a professor of communication at Suffolk University in Boston, Massachusetts. Her research focuses on new media, especially social media, for different demographic groups and how people respond and manipulate technology for their own needs and desires. As a classically trained rhetorician, she believes that the arts and the humanities inform new developments in web design, technology, and communication. Boone is published in leading communication journals such as the Journal of Computer-Mediated Communication, Journal of Communication and Religion, and Public Relations Review. Her research also is in interdisciplinary international journals such as Revista DOXA Comunicacion: Revista Interdisciplinar de estudios de Comunicacion y Ciencias Sociales, and the International Journal of the Humanities. Her website is http://infoacrs.com 